УДК 616.127-008.9-07-085

DOI: $10.26435 /$ UC.V0I4(37).440

\author{
И.С. Греков, М.В. Грушина
}

ГОО ВПО «Донецкий национальный медицинский университет имени М. Горького», Донецк

\title{
МЕТАБОЛИЧЕСКАЯ КАРДИОМИОПАТИЯ: СОВРЕМЕННЫЙ ВЗГЛЯД НА ПРОБЛЕМУ
}

\section{ЦЕЛЬЛЕКЦИИ}

Ознакомить студентов и врачей-интернов с современными представлениями о классификации, этиопатогенезе и клинической диагностике метаболических поражений миокарда.

\section{АК Т УА Л ь О С Т b}

На сегодняшний день наиболее актуальным вопросом современной клинической кардиологии остается проблема функциональных расстройств сердечно-сосудистой системы. Точные данные, отражающие распространенность подобной патологии среди пациентов с поражением сердца, до сих пор остаются неизвестными. Причиной этого могут служить нерешенные вопросы относительно классификации и терминологии функциональных болезней сердца. Однако среди множества патологических состояний, которые можно отнести к потенциально обратимой кардиальной патологии, особое место занимают метаболические расстройства, приводящие к временной или стойкой дисфункции сердечной мышцы. В литературе можно встретить несколько терминов, характеризующих метаболические нарушения в миокарде, - миокардозы, миокардии, миокардиодистрофии, метаболическая кардиомиопатия [1]. Среди отечественных клиницистов наиболее распространен термин «миокардиодистрофия», который впервые был введен и описан Г.Ф. Лангом в 1935 году. В свою очередь термин «метаболическая кардиомиопатия» чаще употребляется в англоязычной литературе и используется в зарубежной клинической практике [1]. При этом данные понятия являются синонимами и описывают единый клинико-патологический процесс. Сам термин “кардиомиопатия” был предложен W. Brigden в 1957 году для обозначения заболеваний миокарда неизвестной этиологии, сопровождающихся значительным увеличением границ сердца, электрокардиографическими изменениями, прогрессирующим течением с разви- тием сердечной недостаточности и в большинстве случаев неблагоприятным прогнозом [2].

Так, в течение последующих 50 лет были предприняты попытки создать универсальную классификацию кардиомиопатий. В 1964 году J. Goodwin предложил классификацию, основанную на структурно-функциональных изменениях в сердце, которая включала несколько форм кардиомиопатий: застойная кардиомиопатия, гипертрофическая кардиомиопатия, констриктивная кардиомиопатия и облитерирующая кардиомиопатия. В 1980 году Всемирная организация здравоохранения представила новую классификацию, включавшую четыре основных типа кардиомиопатий: дилатационную, гипертрофическую, рестриктивную и неклассифицированные кардиомиопатии. В 1995 году той же организацией был добавлен еще один вид кардиомиопатии - аритмогенная кардиомиопатия правого желудочка [3].

На современном этапе наиболее удачной отечественной классификацией, описывающей некоронарогенные заболевания сердца, куда также можно отнести и метаболическое поражение миокарда, является классификация Н.Р. Палеева и Ф.Н. Палеева (2009 год) [4]. В ее основе лежит разделение всех поражений миокарда на миокардиодистрофии, миокардиты, кардиомиопатии и генетически детерминированные поражения миокарда. При этом миокардиодистрофии не совсем тождественны кардиомиопатиям и выделены в отдельную группу вторичных некоронарогенных заболеваний.

Следует иметь в виду, что ни одна из существующих классификаций на данный момент не удовлетворяет полным представлениям об этиопатогенезе подобных поражений миокарда и, соответственно, не может рассматриваться клиницистами как окончательная. Возникшая путаница при использовании термина «кардиомио-

(c) И.С. Греков, М.В. Грушина, 2020

(c) Университетская Клиника, 2020 
патия» требует более совершенной классификации с использованием этиологии и структурнофункциональных критериев.

\section{Общие вопросы метаболических поражений миокарда}

Метаболическая кардиомиопатия - невоспалительное поражение миокарда различной этиологии, в основе которого лежат нарушения процессов образования энергии и обмена веществ, в дальнейшем приводящее к дистрофии миокарда и недостаточности сократительной и других функций сердца [5].

По данным различных исследований, диагностировать такое поражение сердца удается лишь в 25-60\% случаев [6]. Прежде всего, это связано с неспецифическими клиническими и лабораторными проявлениями, а также с тем, что подобное нарушение не является самостоятельной нозологической единицей, а выступает в качестве осложнения ряда других патологических состояний. Ниже приведены основные этиопатогенетические причины возникновения метаболических расстройств в миокарде:

- нарушение жирового и белкового обмена (недостаточное питание, ожирение, заболевания желудочно-кишечного тракта, наследственные заболевания);

- гипо- и авитаминозы;

- эндокринная патология (сахарный диабет, заболевания щитовидной железы, надпочечниковая недостаточность);

- острые и хронические инфекции (в том числе тонзиллит);

- климактерический период;

- анемии;

- электролитный дисбаланс;

- хроническая и острая алкогольная интоксикация;

- воздействие физических факторов (ионизирующее излучение, перегревание, переохлаждение);

- воздействие химических факторов (действие ядов и лекарственных веществ).

При этом в некоторых случаях точное определение метаболических расстройств отражается в наименовании самой кардиомиопатии, например: при поражении органа на фоне гормонального дисбаланса во время климактерического периода говорят о климактерической кардиомиопатии, при поражении вследствие действия патогенных микроорганизмов (при хроническом тонзиллите) - о тонзилогенной кардиомиопатии, при острых или хронических интоксикация алкоголя - об алкогольной кардиомиопатии.

Патофизиологические и патоморфологические аспекты
Общность всех патологических процессов, независимо от этиологии повреждения, сводится к возникновению гипоксического состояния в клетках миокарда. Общее снижение клеточного АТФ приводит к недостаточному сцеплению актина и миозина, вследствие чего адаптивным ответом сердца на снижение сократимости является формирование гипертрофии. Уменьшение продукции энергии в поврежденной сердечной мышце приводит к снижению плотности капилляров, что, наряду с относительно большим диаметром гипертрофированных кардиомиоцитов, ухудшает диффузию кислорода и обусловливает еще большее нарастание гипоксии в клетках. Параллельно с этим развивается митохондриальная дисфункция, что связано с уменьшением окисления жирных кислот, с накоплением липидов в цитоплазме. Чрезмерное накопление жиров и других продуктов метаболизма инициирует процесс апоптоза клеток. Помимо нарушения окисления жирных кислот, нарушаются и процессы окислительного фосфорилирования, в конечном итоге приводящие к изменению кислотного равновесия в сторону ацидоза. Ацидоз в еще большей степени нарушает ряд процессов, участвующих в каскаде «расслаблениесокращение», результатом чего является повышение концентрации кальция в цитозоле и очаговый лизис миофибрилл [5].

В патогенезе всех метаболических нарушений наблюдаются определенные закономерности развития. Основная роль в возникновении большинства метаболических кардиомиопатий принадлежит чрезмерной активации симпатоадреналовой системы и связанной с ней гиперкатехоламинемией. Действие симпатоадреналовой системы прежде всего обусловлено трофическим влиянием на сердечную мышцу. Избыточное содержание катехоламинов в крови приводит к повышению потребности миокарда в энергии, что связано с ингибированием процессов дыхания в митохондриях и большого поступления кальция в кардиомиоциты с одновременным его депонированием в цитоплазме тех же клеток, что ведет к ряду патологических процессов, описанных выше. Большое значение в развитии метаболических кардиомиопатий имеет и активация ренин-ангиотензинальдостероновой системы [6, 7].

Особая роль в возникновении и в особенности прогрессирования метаболической кардиомиопатии принадлежит реакциям свободнорадикального перекисного окисления липидов. При этом повреждаются мембраны и связанные с ними ферменты, которые могут запускать как внешний, так и внутренний путь активации апоптоза [7]. 
Морфологические изменения, происходящие на начальных этапах патофизиологических процессов, в первую очередь затрагивают наиболее чувствительные компоненты клетки - эндоплазматический ретикулум и митохондрии и зачастую являются обратимыми. Поэтому устранение патогенной причины, как правило, приводит к полному восстановлению микроструктур клетки. При длительном и интенсивном воздействии повреждающих факторов на сердечную мышцу развиваются глубокие и необратимые изменения, что выражается в развитии некроза и миокардиофиброза. В результате уменьшения функционирующей части миокарда в оставшихся клетках происходит гиперплазия митохондрий и эндоплазматической сети и других функционально значимых органелл. Итогом таких компенсаторных реакций является гипертрофия миокардиальных клеток. Именно этим объясняется высокая частота гипертрофической формы среди кардиомиопатий метаболического генеза [8].

\section{Некоторые особенности патогенеза при раз-} личных заболеваниях и состояниях

При сахарном диабете в основе нарушения метаболизма миокарда лежит недостаточность инсулина и толерантность к глюкозе. Известно, что гипергликемия ослабляет способность церулоплазмина и альбумина к связыванию сывороточной меди, в результате чего повышается концентрация меди во внеклеточном матриксе, что ведет к увеличению оксидативного стресса и фиброзу посредством стимуляции окислительно-восстановительных реакций кардиомиоцита. Некоторые исследования свидетельствуют в пользу того, что оксидативный стресс может влиять непосредственно на группу клеток СРС (cardiac progenitor cell) - основных предшественников кардиальных клеток, изменяя их функциональные способности [9]. При данной патологии выделяют три основных механизма миокардиального повреждения: нарушение общего клеточного метаболизма, поражение микроциркуляторного русла и нейровегетативную дисфункцию.

В ряде исследований показано, что ренинангиотензин-альдостероновая система при сахарном диабете играет более важную роль в патогенетических механизмах, нежели гиперкатехоламинемия. У пациентов с данной патологией для активации этой системы достаточно лишь небольшой дилатации камер сердца, в то время как у пациентов без сахарного диабета ренинангиотензин-альдостероновая система активируется только во время чрезмерного растяжения миокарда. Однако некоторые авторы полагают, что, наряду с этим, важным фактором ге- неза кардиомиопатий является преобладание так называемых контринсулярных гормонов, и прежде всего глюкокортикоидов, катехоламинов, глюкагона адренокортикотропного и соматотропного гормонов [10].

Патоморфологические изменения сердечной мышцы при сахарном диабете прежде всего связаны с развитием фиброза миокарда. Основой дистрофических изменений служит значительная микроангиопатия с отложением гликопротеинов в стенках сосудов и утолщением их стенок, а также дегенеративные изменения симпатических ганглиев, которые характеризуются потерей синаптических пузырьков и появлением больших вакуолей в этих клетках. Немаловажное значение в фибротических изменениях и функциональных нарушениях играет дисбаланс определенных групп металлопротеиназ и дезорганизация миофибрилл [10, 11].

Патогенез при тиреотоксикозе обусловлен чрезмерным влиянием тиреоидных гормонов на обменные процессы в миокарде, симпатическую иннервацию сердца и гемодинамические характеристики. Гормоны щитовидной железы в больших концентрациях способны влиять на внутриклеточную деятельность митохондрий, нарушают их проницаемость и оказывают прямое влияние на разобщение процессов окислительного фосфорилирования $[5,12]$, в результате чего сократительная способность сердца значительно снижается. Однако на начальных этапах заболевания выявляется повышенная способность миокарда к сокращению. Это связано с непосредственным влиянием тиреоидных гормонов на миокард и изменением симпатического влияния. При этом наблюдаются значительные гемодинамические изменения, связанные с увеличением сопротивления в малом круге и уменьшением в большом более чем на 50 \%. В результате левые отделы сердца испытывают диастолическую перегрузку, а правые как диастолическую, так и систолическую. Нарушение энергетических процессов не позволяет компенсировать работу миокарда увеличением мышечной массы, что, несомненно, ведет к быстрому развитию сердечной недостаточности. Изменение мембранных структур клеток синусового узла приводит к возникновению процессов спонтанной деполяризации и возникновению внеочередных импульсов у таких пациентов [5, 13].

Несмотря на разнообразное влияние тиреоидных гормонов на кардиомиоциты, патологоанатомические изменения в клетке носят неспецифический характер общих дистрофических изменений. 
При наступлении менопаузы основное влияние на обменные процессы всего миокарда оказывает недостаточное количество эстрогенов в организме, в результате чего, помимо снижения метаболизма клетки, наблюдается нарушение метаболизма во всем организме. Особое значение придают климактерической гипертензии, обусловленной нарушенной регуляцией сосудистого тонуса при гипоэстрогении и отсутствием депрессорного воздействия фолликулярного гормона [5].

Патоморфологические изменения в миокарде носят обратимый характер и очень редко заканчиваются развитием фибротических изменений.

При алкогольном поражении сердца метаболическая кардиомиопатия развивается вследствие токсического действия ацетальдегида на органеллы клетки и основные пути утилизации энергии. Непрямое воздействие алкоголя на сердце связано с влиянием на функциональный аппарат надпочечниковых структур и нервную регуляцию.

Характерной особенностью морфологических изменений является жировая дистрофия клеток миокарда. Отмечается развитие отека клеточных структур, исчезновение исчерченности кардиомиоцитов, изменение мембранных структур клеток сердечной мышцы и нейронов сердца [14].

При нарушении жирового обмена, в частности при ожирении, наблюдается изменение свойств адипоцитов, которые начинают активно продуцировать ряд веществ, способных изменять сосудистый тонус. Параллельно изменяется уровень адипонектина - основного белкарегулятора липидного обмена в тканях. В результате происходит стимуляция симпатической нервной системы, высвобождение минералокортикоидов и стимуляция гипоталамогипофизарной системы. Роль последней заключается в контроле потребления пищи. При ожирении наблюдается нарушение функционирования данной системы, что приводит к мотивации потребления пищи в избыточном количестве и отсутствию обратной связи, обеспечивающей устойчивый гомеостаз. Огромную роль в патогенезе кардиомиопатий метаболического генеза при ожирении играет развитие инсулинорезистентности и, соответственно, гиперинсулинемии. В результате этого нарушается электролитный обмен, что способствует развитию артериальной гипертензии [15]. Увеличенный объем циркулирующей жидкости ведет к перегрузке левых отделов сердца и формированию гипертрофии миокарда (при ожирении часто наблюдается развитие диффузной гипертрофии сер- дечной мышцы). Компенсаторно увеличивается ударный объем, который может достигать 10 литров в минуту, при этом треть этого объема идет на кровоснабжение жировой ткани. Изменение гемодинамики способствует формированию сократительной дисфункции, что в конечном итоге ведет к гипоксии миокарда и формированию необратимых дистрофических изменений $[5,15$, 16].

При макроскопическом исследовании сердца отмечается так называемое cor adiposum - атрофия мышечных волокон с замещением их жировой тканью.

\section{Клинико-диагностические особенности ме-} таболических кардиомиопатий

Данный вид поражения миокарда не имеет характерной клинической картины и зачастую протекает бессимптомно, что и составляет определенные диагностические трудности. Основными проявлениями такой патологии являются симптомы основного заболевания. Однако при физикальном осмотре нередко можно выявить приглушенность тонов и наличие шумов, особенно в области верхушки сердца с одновременным расширением границ органа. В анамнезе таких пациентов будет отмечаться дискомфорт в области груди с кардиалгическими проявлениями. В некоторых случаях отмечается наличие отеков, одышки и других ишемических эквивалентов, которые требуют проведения дифференциальной диагностики с инфарктом миокарда. Необходимо отметить, что выраженная сердечная недостаточность развивается относительно редко и в основном встречается в конечной стадии заболевания.

Основным в диагностике всех метаболических нарушений миокарда являются электрокардиографические данные. В дифференциальной диагностике могут иметь значение нагрузочные и медикаментозные пробы, а в случае необходимости - проведение коронарографии [5].

\section{Клиническая картина поражения миокарда при сахарном диабете}

Характерным признаком диабетической кардиомиопатии является быстрое прогрессирование фиброза с развитием диастолической дисфункции. Систолическая дисфункция, как правило, возникает позже и обычно следует за диастолической. Нейропатия у таких пациентов приводит к возникновению тахикардии в покое и появлению болей в предсердечной области. Следует иметь в виду, что пациенты с ювенильной формой сахарного диабета могут не отмечать кардиалгических проявлений вовсе [6, 17]. Нередко наблюдаются клинические признаки сердечной недостаточности. 
Диагностика диабетической кардиомиопатии

Электрокардиографические признаки диабетического поражения сердца не являются строго специфичными. Довольно часто можно наблюдать нарушение внутрижелудочковой проводимости, изменение сегмента ST и уплощение зубца Т. Приступы тахикардии встречаются намного чаще, чем брадикардии.

Значение ультразвукового исследования при данной патологии не всегда однозначно. Так, следует помнить, что диастолическая дисфункция часто не обнаруживается во время стандартной двухмерной эхокардиографии. В то же время использование допплерографии для выявления изменения пиковой систолической скорости кровотока позволяет обнаружить систолическую дисфункцию у $24 \%$ пациентов с сахарным диабетом без сопутствующего ишемического повреждения сердца и/или гипертрофии левого желудочка. Диабетическая кардиомиопатия может выявляться даже у пациентов без клинических проявлений, с нормальной функцией и размерами левого желудочка в покое. У таких пациентов дисфункцию левого желудочка на ранних стадиях заболевания можно спровоцировать физической нагрузкой [8]. Таким образом, исследование сердечной деятельности после физической нагрузки может помочь в выявлении ранней сократительной дисфункции у пациентов с данным заболеванием.

\section{Клиническая картина кардиомиопатии при тиреотоксикозе}

Помимо таких общих неспецифических проявлений, как повышенная возбудимость, слабость в мышцах, потливость, тремор верхних конечностей, потеря веса, для «тиреотоксического сердца» характерен ряд патогномоничных признаков. В первую очередь это касается жалоб на возникновение учащенного сердцебиения в состоянии покоя, которое усиливается еще больше во время даже небольшой физической нагрузки. При этом больные часто отмечают появление болей колющего характера, порой напоминающие стенокардитические, в области сердца. При физикальном осмотре может отмечаться пульсация в предсердечной области. Во время аускультации наблюдается увеличение громкости первого тона с систолическим шумом на верхушке. При измерении системного артериального давления отмечаются его повышенные значения. Для таких больных характерна одышка в покое и быстрое развитие правожелудочковой сердечной недостаточности $[5,12]$.

\section{Диагностика тиреотоксического поражения сердия}

При тиреотоксическом поражении миокарда зачастую требуется дифференциальная ди- агностика с ишемическим повреждением, так как наблюдаются классические электрокардиографические признаки острого инфаркта миокарда. Ключевым моментом такой диагностики является наличие высоких значений свободного тироксина и снижение тиреотропного гормона. Также на ЭКГ могут отмечаться увеличенные зубцы Р и нарушение ритма в виде фибрилляции предсердий. При Эхо-КГ отмечается снижение общей сократительности миокарда.

\section{Клиническая картина при климактерической кардиомиопатии}

Для таких больных характерно наличие кардиалгии частого и продолжительного характера, которая не провоцируется психическим или эмоциональным перенапряжением. Появляется ощущение нехватки воздуха и «неудовлетворенности вдохом». Очень четко прослеживаются основные проявления климактерического синдрома - от эмоциональной лабильности до ухудшения когнитивных функций. При этом последствием таких изменений может быть развитие симптоматической артериальной гипертензии. При мужском климаксе могут отмечаться расстройство мочеиспускания, снижение полового влечения и потенции. При объективном обследовании у таких пациентов обычно отмечается несоответствие между обилием жалоб и отсутствием действительных клинических признаков коронарной или сердечной недостаточности.

\section{Диагностика климактерических поражений миокарда}

K основным электрокардиографическим проявлениям относят изменения зубца T в V1V4. При этом характер изменения может проявляться чередованием периодов элевации и депрессии зубцов, которые не совпадают с клиническими проявлениями. Нередко определяются нерегулярные сокращения с возникновением желудочковых экстрасистол.

При дополнительных методах визуализации миокарда специфических признаков не наблюдается, если к основному поражению не присоединяется ишемическая болезнь сердца $[18,19]$.

Клиническая картина и диагностика поражения сердца при алкогольной интоксикации

В анамнезе таких больных, как правило, фигурирует частое и хроническое злоупотребление алкоголем. При этом ранним проявлением подобной кардиомиопатии являются появление приступов тахикардии и одышки при выполнении умеренной физической нагрузки. Для таких пациентов характерно наличие нарушения ритма в виде желудочковых экстрасистолий, фибрилляции предсердий (что позволяет заподозрить наличие алкогольного поражения мио- 
карда у мужчин молодого возраста при отсутствии других причин, способных вызвать приступы фибрилляции предсердий) и/или нарушения проводимости в виде блокад, что довольно часто наблюдается при однократном употреблении большого количества алкоголя - синдром «праздничного» сердца. [5,20] Нередкой является и картина дилатации левого желудочка с присоединением систолической дисфункции. Также могут отмечаться общие неспецифические симптомы - тремор верхних конечностей, возбуждение, гиперемия лица, потливость, повышение артериального давления и т.п.

Диагностика на раннем этапе заключается в выявлении дистрофических изменений на электрокардиограмме. Данные дополнительных методов исследования также не являются строго специфичными. Поэтому диагноз «алкогольная кардиомиопатия» основывается на комплексной оценке анамнеза, основных и дополнительных методов исследования.

\section{Клиническая картина поражения миокарда при ожирении}

Гемодинамически значимые нарушения могут наступать у пациентов, имеющих индекс массы тела более 40 кг/м2. Однако поражение сердечной мышцы может наступать при показателе в 30 кг/м2. У таких больных отмечается ортопноэ и пароксизмальная ночная одышка, возможны отеки на нижних конечностях. Сердце изменяет свое положение на поперечное. Нарушения ритма и повышенные значения артериального давления также характерны для таких больных, нередко диагностируется синдром Пиквика.

\section{Диагностика кардиомиопатии при ожирении}

На электрокардиограмме отмечаются сниженные сегменты ST в I, II, V5 и V6, а также отклонение электрической оси влево. Возможны признаки гипертрофии, преимущественно левого желудочка. При проведении допплерэхокардиографии определяются признаки диастолической, а позднее и систолической недостаточности. Возможно расслоение листков перикарда за счет отложения жира. Однако метод ультразвукового исследования не всегда является достоверным, за счет изменения положения самого органа. Границы сердца всегда расширены, что особенно хорошо визуализируется на рентгенограмме, причем зачастую такое расширение бывает из-за отложения жира в области верхушки сердца [20, 21].

Общие аспекты терапии метаболического повреждения миокарда

Лечение метаболической кардиомиопатии начинается с устранения этиологического фактора. При этом, независимо от причины, следу- ет ограничить воздействие стрессовых факторов, в том числе курения и употребление спиртного. Следует всегда помнить, что все метаболические нарушения миокарда всегда обратимы при своевременном их лечении. Поэтому параллельно с устранением основной патологии необходимо применить комплекс мероприятий, направленных на недопущение развития тяжелой гипоксии клеток, то есть восстановить процессы транспорта кислорода и его утилизации. В последнее время большое внимание уделяют роли серотонинергической системы в регуляции стрессорной реакции. С этой целью используют никотинамид, который проявляет способность стимулировать процессы аэробного окисления и обмен гликогена, тем самым повышая устойчивость кардиомиоцитов к гипоксии. Прямое цитопротекторное действие на сердечную мышцу в условиях гипоксии оказывает триметазидин. Помимо устранения гипоксии, следует откорректировать и основной обмен в клетке. Это достигается определенным рядом биологически активных веществ гормональной природы, витаминов, стимуляторами и блокаторами вегетативной нервной системы, ферментами и другими метаболитами. Например, при нарушениях окислительного фосфорилирования используют витамины группы В (B1 и В2), липоевую и пантотеновую кислоты. Витамины группы E, C, а также никотиновую кислоту применяют в качестве антиоксидантов, тем самым уменьшают цитотоксическое воздействие свободных радикалов. Для нормализации функции миокарда огромное значение имеет своевременное и достаточное поступление аминокислот в клетки. Для улучшения их усвоения рекомендуется назначать их в комплексе с анаболическими стероидами (нандролон, метандиенон). А чтобы максимально усилить процессы биосинтеза белка, назначают соли оротовой кислоты $[5,20]$.

Коррекцию ионного состава осуществляют преимущественно при прогрессировании дистрофических изменений в миокарде. При этом используют калия хлорид, магния аспарагинат. Продолжительность интенсивной метаболической терапии на ранних стадиях у пациентов с преимущественно функциональными нарушениями составляет около трех недель. При прогрессировании дистрофических изменений и выявлении органического поражения сердца курс терапии повторяют несколько раз в год.

В остальном лечение подобной патологии заключается в симптоматической терапии. При лечении артериальной гипертензии назначают ингибиторы ангиотензин превращающего фермента, диуретики, бета-адреноблокаторы [5, $10,22]$. Лечение сердечной недостаточности не 
имеет специфической терапии, однако следует иметь в виду, что в большинстве случаев сердечная недостаточность при метаболической кардиомиопатии резистентна к сердечным гликозидам и успех терапии целиком зависят от степени восстановления нарушенного обмена веществ в миокарде.

\section{ЗАК ЛЮЧЕНИЕ}

Метаболические поражения миокарда составляют значительную долю среди всех функциональных и некоронарогенных заболеваний сердца. Поэтому знание врача об особенностях клиники и диагностики различных вариантов метаболических расстройств сердечной мышцы способствует своевременной и правильной диагностике и выбору тактики ведения таких больных, что в свою очередь позволит избежать различных осложнений.

\section{И.С. Греков, М.В. Грушина}

ГОО ВПО «Донецкий национальный медицинский университет имени М. Горького», Донецк

\section{МЕТАБОЛИЧЕСКАЯ КАРДИОМИОПАТИЯ: СОВРЕМЕННЫЙ ВЗГЛЯД НА ПРОБЛЕМУ}

Цель лекции - ознакомить студентов медицинских вузов, врачей-интернов с этиологией, патогенезом, клиническими проявлениями, а также с особенностями диагностики и терапии метаболических нарушений миокарда. Актуальной проблемой современной кардиологической практики является вопрос функциональных расстройств миокарда, к которым и принадлежат метаболические кардиомиопатии. Под метаболической кардиомиопатией подразумевают невоспалительное поражение миокарда различной этиологии, в основе которого лежит нарушение процессов метаболизма, проявляющееся в недостаточности основных функций органа. Многообразие факто- ров и состояний, приводящих к возникновению подобных нарушений, а также неспецифичность клинических проявлений позволяют говорить о мультидисциплинарном характере заболевания, что зачастую требует лечение таких больных врачами разных специальностей. Материал лекции может быть использован при проведении циклов очной и последипломной подготовки студентов медицинских вузов, врачей общей практики, врачей-кардиологов, врачейэндокринологов.

Ключевые слова: метаболическая кардиомиопатия, миокардиодистрофия, сахарный диабет, гипертиреоз, ожирение.

\section{I.S. Grekov, M.V. Grushina}

\section{SEI HPE «M. Gorky Donetsk National Medical University», Donetsk}

\section{METABOLIC CARDIOMYOPATHY: A MODERN VIEW OF THE PROBLEM}

The purpose of the lecture is to acquaint medical students and interns with the etiology, pathogenesis, clinical manifestations, as well as with the features of diagnosis and therapy of metabolic disorders of the myocardium. An actual problem of modern cardiological practice is the question of functional disorders of the myocardium, which include metabolic cardiomyopathy. Under metabolic cardiomyopathy mean non-inflammatory myocardial damage of various etiologies, which is based on a violation of the metabolic processes, manifested in the insufficiency of the main functions of the organ. The variety of factors and conditions that lead to the occur- rence of such disorders, as well as the non-specific clinical manifestations allow us to speak about the multidisciplinary nature of the disease, which often requires treatment of such patients by doctors of different specialties. The material of the lecture can be used during the cycles of full-time and postgraduate training of medical students, General practitioners, cardiologists, endocrinologists.

Key words: metabolic cardiomyopathy, myocardiodystrophy, diabetes mellitus, hyperthyroidism, obesity.

\section{ЛИТЕРАТУРА}

1. Обрезан А.Г. Дискуссионные вопросы кардиологии: «кардиомиопатия» или «миокардиодистрофия»? Вестник Санкт-Петербургского университета, 2014; 3: 192208.

\section{REFERENCES}

1. Obrezan A.G. Diskussionnye voprosy kardiologii: «kardiomiopatija» ili «miokardiodistrofija»? Vestnik Sankt-Peterburgskogo universiteta, 2014; 3: 192-208 (in Russian).

2. Brigden W. Uncommon myocardial diseases. The noncoro- 
2. Brigden W. Uncommon myocardial diseases. The noncoronary cardiomyopathies. Lancet. 1957; 2: 1179-1184.

3. Richardson P., McKenna W., Bristow M., et al. Report of the 1995 World Health Organization International Society and Federation of Cardiology Task Force on the Definition and Classification of cardiomyopathies. Circulation. 1996; 93 (5): 841-842.

4. Палеев Н.Р., Палеев Ф.Н. Некоронарогенные заболевания миокарда и их классификация. Российский кардиологический журнал, 2009; 77 (3): 5-9.

5. Руководство по кардиологии. Под ред. В.Н. Коваленко. - К.: Издательство Морион, 2008: 994-1011.

6. Леонтьева И.В., Белозеров Ю.М., Сухоруков В.С., Николаева В.А. Проблемы современной диагностики метаболических кардиомиопатий. Российский вестник перинатологии и педиатрии, 2012; 4 (1): 55-63.

7. Порядин Г.В. Молекулярные механизмы повреждения клеток. Методические разработки. М. 1997; 50.

8. Драпкина О.М., Гегенава Б.Б. Диабет и сердце - поражение миокарда при диабетической кардиомиопатии. Эндокринология: новости, мнения, обучение, 2015; 3: 84-92.

9. Rota M. et al. Diabetes promotes cardiac stem cell aging and heart failure, which are prevented by deletion of the p66shc gene. Circ Res. 2006; Vol. 99 (1): 42-52.

10. Fang Z.Y., Prins J.B., Marwick T.H. Diabetic cardiomyopathy: evidence, mechanisms, and therapeutic implications. Endocrine Reviews. 2004; Vol. 25: 542-567.

11. Bartnik M., Van der Berghe G., Betteridge J. et al. Guidelines on diabetes, prediabetes and cardiovascular diseases. Eur. Heart J., 2007; 28: 90-127.

12. Бабенко А. Ю. Тиреотоксическая кардиомиопатия: факторы риска и предикторы развития. Обзоры по клин. фармакол. и лек. терапии. 2011; Т.9; 3: 4959.

13. Бабенко А. Ю. Влияние субклинического тиреотоксикоза различного генеза на сердечно-сосудистую систему. Учен. записки СПбГМУ им. И. П. Павлова. 2006; Т.13; 4: 65-67.

14. Фадеев Г.А., Цибулькин Н.А., Михопарова О.Ю., Тахватуллина Г.В. Патогенетические механизмы развития алкогольной кардиомиопатии. Вестник современной клинической медицины. 2019; 12 (4): 74-79.

15. Чумакова Г.А., Веселовская Н.Г., Козаренко А.А., Воробьева Ю.В. Особенности морфологии, структуры и функции сердца при ожирении. Российский кардиологический журнал, 2012; 4 (96): 94-98.

16. Рагино Ю.И., Тимошенко Н. А., Чернявский А.М., Цымбал С.Ю., Щербакова Л.В., Воевода М.И. Связь компонентов метаболического синдрома с электрокардиографическими биомаркерами метаболической кардиомиопатии у мужчин с коронарным атеросклерозом. Российский кардиологический журнал, 2015; 4 (120): 68-72.

17. Towbin J.A., Lowe A.M., Colan S.D. et al. Incidence, causes, and outcomes of dilated cardiomyopathy in children. JAMA, 2006; 296: 1868-1875.

18. Шостак Н.А., Якушин С.С., Филиппов Е.В. Кардиомиопатии. Кардиология. Национальное руководство. Под ред. Ю. Н. Беленкова, Р. Г. Оганова. М: ГЭОТАР-Медиа, 2007; 887-899.

19. Ardehali H., Kasper E.K., Baughman K.L. Diagnostic approach to the patient with cardiomyopathy: whom to biopsy. Amer. Heart J., 2005; 149: 9-12.

20. Юсупова А.О. Алкогольная кардиомиопатия: основные аспекты эпидемиологии, патогенеза и лекарственной терапии. Рациональная фармакотерапия в кардиологии, 2014; 10 (6): 651-658.

21. Hashimoto N., Kanda J., Nakamura T., et al. Association of hypoadiponectinemia in men with early onset of coronary heart disease and multiple coronary artery stenoses. Metabolism , 2006; 55: 1654-1656.

22. Mattar C.N., Harharah L., Su L. L.et al. Menopause, hormone therapy and cardiovascular and cerebrovascular disease. Ann Acad Med Singapore. 2008; 1: 55-60. nary cardiomyopathies. Lancet. $1957 ; 2: 1179-1184$

3. Richardson P., McKenna W., Bristow M., et al. Report of the 1995 World Health Organization International Society and Federation of Cardiology Task Force on the Definition and Classification of cardiomyopathies. Circulation. 1996; 93 (5): 841-842.

4. Paleev N.R., Paleev F.N. Nekoronarogennye zabolevanija miokarda i ih klassifikacija. Rossijskij kardiologicheskij zhurnal, 2009; 77 (3): 5-9 (in Russian).

5. Rukovodstvo po kardiologii. Pod red. V.N. Kovalenko. - K.: Izdatel'stvo Morion, 2008: 994-1011 (in Russian).

6. Leont'eva I.V., Belozerov Ju.M., Suhorukov V.S., Nikolaeva V.A. Problemy sovremennoj diagnostiki metabolicheskih kardiomiopatij. Rossijskij vestnik perinatologii i pediatrii, 2012; 4 (1): 55-63 (in Russian).

7. Porjadin G.V. Molekuljarnye mehanizmy povrezhdenija kletok. Metodicheskie razrabotki. M. 1997; 50 (in Russian).

8. Drapkina O.M., Gegenava B.B. Diabet i serdce - porazhenie miokarda pri diabeticheskoj kardiomiopatii. Jendokrinologija: novosti, mnenija, obuchenie, 2015; 3: 84-92 (in Russian).

9. Rota M. et al. Diabetes promotes cardiac stem cell aging and heart failure, which are prevented by deletion of the p66shc gene. Circ Res. 2006; Vol. 99 (1): 42-52.

10. Fang Z.Y., Prins J.B., Marwick T.H. Diabetic cardiomyopathy: evidence, mechanisms, and therapeutic implications. Endocrine Reviews. 2004; Vol. 25: 542-567.

11. Bartnik M., Van der Berghe G., Betteridge J. et al. Guidelines on diabetes, prediabetes and cardiovascular diseases. Eur. Heart J., 2007; 28: 90-127.

12. Babenko A. Ju. Tireotoksicheskaja kardiomiopatija: faktory riska i prediktory razvitija. Obzory po klin. farmakol. i lek. terapii. 2011; T.9; 3: 49-59 (in Russian).

13. Babenko A. Ju. Vlijanie subklinicheskogo tireotoksikoza razlichnogo geneza na serdechno-sosudistuju sistemu. Uchen. zapiski SPbGMU im. I. P. Pavlova. 2006; T.13; 4: 6567 (in Russian).

14. Fadeev G.A., Cibul'kin N.A., Mihoparova O.Ju., Tahvatullina G.V. Patogeneticheskie mehanizmy razvitija alkogol'noj kardiomiopatii. Vestnik sovremennoj klinicheskoj mediciny. 2019; 12 (4): 74-79 (in Russian).

15. Chumakova G.A., Veselovskaja N.G., Kozarenko A.A., Vorob'eva Ju.V. Osobennosti morfologii, struktury i funkcii serdca pri ozhirenii. Rossijskij kardiologicheskij zhurnal, 2012; 4 (96): 94-98 (in Russian).

16. Ragino Ju.I., Timoshenko N. A., Chernjavskij A.M., Cymbal S.Ju., Shherbakova L.V., Voevoda M.I. Svjaz' komponentov metabolicheskogo sindroma s jelektrokardiograficheskimi biomarkerami metabolicheskoj kardiomiopatii u muzhchin s koronarnym aterosklerozom. Rossijskij kardiologicheskij zhurnal, 2015; 4 (120): 68-72 (in Russian).

17. Towbin J.A., Lowe A.M., Colan S.D. et al. Incidence, causes, and outcomes of dilated cardiomyopathy in children. JAMA, 2006; 296: 1868-1875.

18. Shostak N.A., Jakushin S.S., Filippov E.V. Kardiomiopatii. Kardiologija. Nacional'noe rukovodstvo. Pod red. Ju. N. Belenkova, R. G. Oganova. M: GJeOTAR-Media, 2007; 887899 (in Russian).

19. Ardehali H., Kasper E.K., Baughman K.L. Diagnostic approach to the patient with cardiomyopathy: whom to biopsy. Amer. Heart J., 2005; 149: 9-12.

20. Jusupova A.O. Alkogol'naja kardiomiopatija: osnovnye aspekty jepidemiologii, patogeneza i lekarstvennoj terapii. Racional'naja farmakoterapija v kardiologii, 2014; 10 (6): 651-658 (in Russian).

21. Hashimoto N., Kanda J., Nakamura T., et al. Association of hypoadiponectinemia in men with early onset of coronary heart disease and multiple coronary artery stenoses. Metabolism , 2006; 55: 1654-1656.

22. Mattar C.N., Harharah L., Su L. L.et al. Menopause, hormone therapy and cardiovascular and cerebrovascular disease. Ann Acad Med Singapore, 2008; 1: 55-60. 